III. Abnormalities permitting acceptance, but to be reported to the camp surgeon with a request that the recruit be watched during training.-1. Persistent extrasystoles, if only impairment.

2. History of attacks of severe tachycardia with dyspnea.

3. Normal heart, but with poor response to exercise, and with a past history of incapacity for physical exertion.

IV. Abnormalities which permit a recommendation for special service requiring little bodily excrtion. -1 . Dilatation of the aorta, or syphilitic aortitis, if without symptoms.

2. Systolic blood pressure more than 160 , but less than 200 ; or a diastolic more than 100 and less than 120 , if persistent.

3. Heart normal, but with the response to exercise impaired, and a past history of incapacity for bodily exertion.

SIGNS OF VASOMOTOR INSTABILITY

The cases that gave us the greatest difficulty in decision were the tachycardias, with the pulse ranging from about 120 , when the recruit was standing, up to 140,160 or 180 after exercise. After a time we learned to separate these men into three groups:

1. The cases of purely nervous tachycardias, in casily disturbed persons. Some of the recruits had a history of a rapid pulse whenever examined. Some were excited for fear of rejection, and a very few for fear they would not be rejected. The tachycardias in these cases, as well as the rapid pulses due to exertion immediately before examination, were for the most part easily eliminated by a few minutes of quiet, with the recruit in a recumbent position, or if not by this, by a reexamination a day or two later.

2. The cases of tachycardia which showed a barely perceptible thyroid enlargement, slight tremor, moderate dermatographia, and other signs of vasomotor instability, but no eye symptoms. These were by far the most difficult to decide, and were very much more common than our civil practice would suggest. The majority of the men were of excellent physique and were keen for service, but were excitable and perhaps somewhat on the so-called neurasthenic order. Clinically, one would make a diagnosis of a mild hyperthyroidism, or beg the question of etiology by calling it vasomotor ataxia of unknown origin. It was so hard to decide about these men that on one occasion we had a special examination of a baker's dozen. Each one was examined by every member of the board at Camp Mills, and the question of acceptance or rejection voted on by the whole board for each subject. Most of the men were accepted, but the voting was by no means unanimous. This incident is mentioned simply to show that, even after a fairly large experience, there is room for difference of opinion in these puzzling cases.

Several of us believed, and still believe, that such men, desirable as they may be in all other respects, will not be able to stand the strain of service. This opinion has been voiced by Osler, ${ }^{1}$ who, to use his own words, "sees the wastage of the recruiting office." $\mathrm{He}$ says: "The trenches are no place for the man with unstable vasomotors. In the strain of war they break like dry twigs, and become a heavy burden on the hospitals and convalescent homes. In all cases, when in doubt, give the country the benefit."

3. Exophthalmic goiter. When there was no doubt as to diagnosis, men with marked exophthalmic goiter were, and should be, rejected.

In this connection, it is of interest to mention the extraordinary prevalence of the plain cystic goiter

1. Osler, Sir William: War Wastage, The Journal A. M. A., July 28,1917, p. 290 in men from certain parts of the country, especially from the northern part of New York and from the other states bordering on the Great Lakes. Provided there were no evidences of hyperthyroidism, these men were nearly all accepted, but were made F. R. O.'s. A negligible few were not accepted because of certain symptoms following exercise, which indicated undue pressure on the trachea-a purely mechanical effect.

As to the tachycardias in general, it may safely be said that it is often impossible in one examination to distinguish with certainty between the nervous and the slight hyperthyroid cases. It should be the rule to reexamine after the lapse of one or more days-a week, if possible. If a second examination is impracticable, the medical officer of the soldier's unit should be requested to keep the latter under observation during his training, that is to say, ascertain the results of a functional test.

226 Gates Avenue.

\section{ACIDOSIS IN SHOCK *}

\section{W. S. McELLROY, B.S., M.D. PITTSBURGH}

At the suggestion of the National Research Council, extensive investigations on shock have been undertaken. Numerous theories have been offered as to the cause of the condition termed "shock." One attributes the condition to acidosis, and sodium bicarbonate has been suggested in the treatment.

In connection with observations on shock carried on in this laboratory, a preliminary report of which has been published, ${ }^{1}$ studies on the acidosis factor were undertaken. The results of these observations form the context of this report.

\section{METHODS OF EXPERIMENTATION}

The method of producing shock and judging of the condition has been described in a previous report." Essentially, they comprise prolonged strong rhythmic stimulation of the afferent nerves of dogs, under ether anesthesia. Under such circumstances the time required to establish the condition varied greatly in different animals. When necessary, the onset of the condition was hastened by other means, such as exposure and manipulation of the abdominal viscera. In later experiments peripheral nerve stimulation combined with partial cerebral anemia was found to be the most satisfactory procedure yet employed in refractory cases. ${ }^{2}$ Anemia was produced by temporary occlusion of arteries supplying the medulla and brain. It should be noted that blood was always lost, but the quantity was not great, being limited to the amount unavoidably escaping from operative procedures and samples withdrawn at intervals for analyses.

The methods used for studying acidosis were the indicator methods of Levy, Rowntree and Marriott for $\mathrm{H}$-ion concentration ${ }^{3}$ of Marriott for reserve alkalinity, ${ }^{4}$ and of Van Slyke for plasma bicarbonate. ${ }^{5}$

* From the Laboratory of Physiological Chemistry, University of Pittsburgh School of Medicine.

2. Guthrie, C. C.: Observations in Shock, Proc. Am. Physiol. Soc., 1917; Am. Jour. Physiol., to be published.

3. Levy, R. L.; Rowntree, L. G., and Marriott, W. M.: A Simple Method for Determining Variations in the Hydrogen-Ion Concentration Method for Determining Variations in the Hydrogen-Ion
of the Blood, Arch. Int. Med., September, 1915, p. 389.

4. Marriot, W. M. A Method for the Determination of the Alkali Reserve of the Blood Plasma, Arch. Int. Med., June, 1916, p. 840.

c. Vin Sivke, Donald D.: A Method for the Determination of Carbon Dioxid and Catbonates in Solution, Jour. Biol. Chem., 1917, it $0,34 \pi$. 
In the early experiments, the indicator methods for $\mathrm{H}$-ion concentration and reserve alkalinity being used, variations in different animals were found. In some cases there was no change, while in others there was an increase in concentration. The greatest variations occurred in reserve alkalinity.

In later experiments aimed primarily at the acidosis factor, Van Slyke's method for plasma bicarbonate was employed. This method was chosen, first, because the preliminary experiments showed greatest changes in reserve alkalinity, and in some cases no change in the $\mathrm{H}$-ion concentration itself. Secondly, because our use of the term acidosis is based on the work of Henderson, ${ }^{6}$ Van Slyke ${ }^{7}$ and others, namely, that the blood bicarbonate is the criterion of the acid base balance of the body.

Van Slyke's technic was followed in detail. Blood samples were drawn from the femoral vein by the syringe method. Coagulation was prevented by neutral potassium oxalate. The blood was immediately centrifuged and the plasma removed, saturated with the expired air of the operator, and 1 c.c. taken for analysis.

\section{RESULTS}

1. Plasma Bicarbonate in Ether Anesthesia-The observations on normal dogs before the administration of ether have fallen within the range for normal adults given by Van Slyke (from 53 to 77 per cent. of carbon dioxid by volume). Following the administration of ether a considerable decrease in the plasma bicarbonate was noted. We have observed that under anesthesia only, before the measures employed to induce shock were begun, the bicarbonate content of the plasma ranged between 40 and 50 per cent. of carbon dioxid by volume. In one case, we observed 55.7 per cent. of carbon dioxid by volume under ether anesthesia. This was due, no doubt, in part to the muscular activity associated with the administration of the anesthetic.

2. Plasma Bicarbonate in Shock.-In general there was a gradual decrease in reserve alkalinity associated

PLASMA BICARBONATE IN SHOCK

Per Cent. of Carbon Dioxid by Volume

Before shock production, immediately after admin istration of anesthetic $\ldots \ldots \ldots \ldots \ldots \ldots \ldots . \ldots 5.7$ During period of shock production ............ 51.9 Animal showing symptoms of profound shock.... 49.0

40.0
40.0

40.0
35.3

with shock production. The results obtained in shock ranged between 35 and 45 per cent. of carbon dioxid by volume. The amount of decrease varied in different animals. In some cases the results were very slight, being only 5 per cent. of carbon dioxid by volume; in others they were more marked, 10 per cent. of carbon dioxid by volume being observed. Two animals were reduced to a profound state of shock, showing a bicarbonate content of plasma within the range of other animals before shock production. The results of two experiments illustrating this point are given in the accompanying tabulation.

3. Injection of Sodium Bicarbonate in Shocked Animals.-The injection of sodium bicarbonate in shocked animals brought the reserve alkalinity back to the

6. Henderson, L. J.: The Theory of Neutrality Regulation in the Animal Organism, Am. Jour. Physiol., 1908, 21, 427; Das Gleichgewicht zwischen Basen und Säuren im tierischen Organismus, Ergebn. d. Physiol., 1909, 8, 254.

Biol. Chem., 1917, 30, 289 . upper limit of normal. This return of reserve alkalinity to normal was not associated with improvement in the condition of the animal in excess of that probably due to the volume of fluid injected.

4. Shock Production Without Decrease in Reserve Alkalinity.-By the injection of sodium bicarbonate the reserve alkalinity was maintained within the normal range. By the usual methods, the animal was reduced to a state of profound shock. No increased resistance to shock was noted by so maintaining the reserve alkalinity.

5. Experimental Acidosis. - By the intravenous injection of lactic acid a primary acidosis was produced. By the injection of acid the reserve alkalinity could be lowered at will. When the reserve alkalinity had been lowered within the range observed in shockes animals, no change could be noted in the condition of the animal. It was necessary to lower the reserve alkalinity from 10 to 15 per cent. of carbon dioxid by volume below the range of shocked animals before a material fall in blood pressure occurred. The further injection of acid produced a rapid fall in blood pressure to a very low level, with cardiac and respiratory failure. At this point artificial respiration and cardiac massage alone were ineffectual, but, combined with the injection of sodium bicarbonate, produced prompt recovery and return of reserve alkalinity to normal.

SUMMARY OF RESULTS

In the type of experimental shock studied there was a gradual decrease in the reserve alkalinity of the blood. The decrease varied in different animals. Anesthesia was an important factor. In some instances, the reserve alkalinity in shock was as great as in other animals before shock. This shows that acidosis was not an important causative factor. In no case was a change in reserve alkalinity sufficient to account for the condition observed.

In experimental primary acidosis the alkali reserve may be lowered to a degree observed in shock without producing any marked change in the condition of the animal.

The injection of sodium bicarbonate into animals reduced to a terminal state by injection of acid resulted in prompt recovery.

The injection of sodium bicarbonate into animals in shock was without beneficial action, although the reserve alkali was restored.

Shock may be induced while the alkali reserve is maintained by injection of sodium bicarbonate.

\section{CONCLUSION}

In the type of experimental shock studied, acidosis was not the cause but one of the many secondary changes associated with the condition.

Health Conditions in Newark.-The death rate of Newark during 1917, according to the Monthly Bulletin of the department of health, was 15.3 per thousand on an estimated population of 405,000 , as against a rate of 16.5 for 1916 . There was a total of 6,205 deaths, the figures for the extreme of life being 1,461 under 5 years and 2,892 at 45 and above. There were 11,824 births, a rate of 29.1 per thousand, as against 29.7 for 1916. There were 1,038 deaths under 1 year, a rate of 87.8 per thousand births. This is a decrease of 1.8 from the rate for 1916. Deaths for the six chief contagious diseases, including poliomyelitis, were 304 as against 851 for 1916 when the epidemic of poliomyelitis swelled the figures, which were 376 for 1916, as against 11 for 1917 . 